\title{
THE EFFECTIVENESS OF MELATONIN IN REDUCING PAIN RESULTING FROM RADIATION INDUCED ORAL MUCOSITIS: A RANDOMIZED CLINICAL TRIAL
}

\author{
Hossam H. Elsabbagh ${ }^{*}$ BDs, Eglal Moussa ${ }^{2}$, Sabah A. Mahmoud ${ }^{3}$, Rasha $O$.
} Elsaka 4

\section{ABSTRACT}

BACKGROUND: Oral mucositis is a common side effect of anticancer radiotherapy causing severe ulceration of the mucosal tissues. Recently, melatonin supplements have been proposed as a new therapeutic modality for oral mucositis due to its antioxidant effects, anti-inflammatory, and anti-cancer properties.

OBJECTIVES: evaluation of the effectiveness of melatonin in reducing pain resulting from radiation induced oral mucositis

MATERIALS AND METHODS: Forty patients were randomly assigned to receive either: conventional treatment of oral mucositis, or 20 mg melatonin treatment in combination with the conventional treatment before irradiation, and for six weeks. All patients were evaluated for pain resulting from oral mucositis at three and six weeks after the start of radiotherapy.

RESULTS: Oral mucositis patients in the melatonin group have experienced significantly lower pain scores oral mucositis compared to the control group.

CONCLUSION: Adjuvant melatonin reduced the pain of oral mucositis, and the amount of analgesics used for pain treatment. KEYWORDS: melatonin, oral mucositis, radiotherapy

1. Instructor of Oral Medicine, Periodontology, Oral Diagnosis and Oral Radiology department, Faculty of Dentistry, Alexandria University, Egypt.

2 .Professor of Oral Medicine, Periodontology, Oral Diagnosis and Oral Radiology department, Faculty of Dentistry, Alexandria University, Egypt.

3. Professor of Medical Biochemistry department, Faculty of Medicine, Alexandria University, Egypt. 4.Clinical Oncology and Nuclear Medicine department, Faculty of Medicine, Alexandria Uniyersity, Egypt

*Corresponding author

Hossam.hamdy@alexu.edu.eg

\section{INTRODUCTION}

The emergence of oral mucositis is one of the most crippling toxic side effects of anticancer therapy. It affects $40-80 \%$ of patients receiving chemotherapy and almost all those who have undergone head and neck radiation therapy. (1)

Oral radiation mucositis begins with ionizing radiation in mucosal tissue that interacts with water molecules within cell, resulting in the creation of destructive, partly lowered forms of oxygen called free radicals (2). Due to the unpaired electrons in the free radical external orbit, they are highly reactive and damage most cell macromolecules which lead to lipid peroxidation, mitochondrial dysfunction, damage to cellular DNA and death.(3)

Oral mucositis $(\mathrm{OM})$ is a life-threatening situation, as the associated extreme pain on swallowing (odynophagia) may lead to difficulty in both liquid and solid feeding (dysphagia), resulting in dehydration and malnutrition. In addition to, poor coordination of the speech muscles (dysarthria). Moreover, in severe cases that require endoscopic gastrostomy tube feeding, patients may also suffer from depression due to the deteriorated quality of life. $(4,5)$

The mucosal reaction to cancer therapy cannot be clinically anticipated as several factors affect the development of oral mucositis. These risk factors can be divided into therapy-related and patient- related factors. The latter includes patient age, gender, ethnicity and nutritional status.(6)

With respect to therapy related factors, development of mucositis has been shown to depend on the type of therapy (radiation, chemotherapy, or combined chemo-radiotherapy), dose, and delivery plan. Moreover, multiple studies have shown an increase in the risk of developing oral mucositis as therapy intensity increases.(7) 
In addition , smoking,(8) periodontal disease, oral hygiene status,(9) co-existing illness' and genetic factors(10), might be considered as patient-related variables that could make one patient more susceptible to the development of mucositis than the others.

Based on the understanding of oral mucositis pathogenesis, the main trigger for the tissue destruction is the free radical formation. Therefore, the use of antioxidants is generally accepted for the prevention and treatment of oral mucositis.

Amifostine, a thiol compound which acts as a potent reactive oxygen species (ROS) scavenger, was one of the first antioxidant agents to be used.(11) However, due to its inconsistency, Amifostine has no further recommendations for use in the prevention of oral mucositis.(12)

Another antioxidant agent, which has been proposed to prevent $\mathrm{OM}$ is $\mathrm{N}$-acetyl cysteine (NAC). In a randomized clinical trial conducted by Moslehi A et al. it was concluded that parenteral NAC effectively reduced the incidence and the total duration of $\mathrm{OM}$ by stimulating Glutathione (GSH) synthesis that scayenges free radicals.(13)

Melatonin ( $N$-acetyl-5-methoxy tryptamine) is a natural hormone, that regulates sleep and wakefulness. It is primarily produced by the pineal gland in animals and humans. Typically, its concentration in the body is low during day time and reaches maximum levels in the dark at night. (14)

In addition to its antioxidant properties, Melatonin is an effective free radical scavenger with a potent affinity towards almost all ROS (15). In vitro, it has been shown that melatonin is a very efficient hydroxyl $\left(\mathrm{OH}^{-}\right)$neutralizer. (16) It is, by now, well documented that melatonin decreases oxidative damage to all cellular macro-organelles.(16, 17) Both animal $(18,19)$ and human $(20,21)$ studies have shown melatonin to protect against radiation-induced cellular damage.

Although there are many references in the literature about the use of melatonin oncostatic and cytoprotective properties in the treatment of different human oral conditions $(22,23)$, we still lack clinical trials on the use of melatonin in minimizing the pain resulting from radiation induced oral mucositis.

\section{MATERIALS AND METHODS}

\section{Participants and Study design:}

This randomized, controlled, clinical trial was conducted on forty patients of both sexes who were going to receive radiotherapy on head and neck region. Patients were recruited over one year and had received a detailed explanation of the study and were enrolled after signing an informed consent form according to the guide lines of the ethical committee of the faculty of dentistry, Alexandria university (IRB NO:00010556) - (IORG 0008839)
The study was conducted in accordance with the principles of the modified Helsinki's code for human clinical studies (24) , and CONSORT guidelines for reporting randomized clinical trials.(25)

Sample Size and randomization : A sample size of 20 patients per group (number of group $=2$ ) (total sample size = 40 patients) is the enough required sample to detect an standardized effect size of $27 \%$ change in the primary outcome, (26) as statistically significant with $80 \%$ power and at a significance level of $95 \%$. The sample size was calculated using GPower version 3.1.9.2. (27) Allocation of cases to either treatment approach was conducted randomly using simple randomization procedures (computerized random numbers).(28) To achieve allocation concealment, randomization was performed by an examiner who was not involved in the study. All patients in this study were blind to the type of treatment.

The inclusion criteria of the patients included patients who received radiation therapy either in postoperatory (adjuvant) or as a definitive therapy in the treatment for head and neck cancer. Patients were excluded from the study if treatment planned dose was lower than 60 Gy. into two groups:

The population of the study was divided randomly

Control group in which twenty patients were given conventional treatment which included antifungal agents (Miconaz oral gel), topical anesthetics and anti-inflammatory agent (BBC oral spray), topical analgesic gel (Oracure gel), sodium bicarbonate mouthwash (Alkamisr sachets), three times per day for six weeks. (29)

Test group in which twenty patients were given melatonin therapy (Rapid Release Capsules Melatonin, 10 $\mathrm{mg}$ ) two tablets, 30 minutes before sleeping once daily for six weeks adjuvant to the conventional treatment.(22)

All patients were evaluated and recorded three weeks and six weeks after starting the radiotherapy, based on the following measurement

Discomfort and pain severity were reported by each patient and recorded using the Visual Analogue Scale (VAS). It is represented by horizontal line that is marked with numbers ranging from zero to ten representing extremes of pain intensity (no pain and extreme pain) and categorized to

1- No pain (VAS 0)

2- Mild pain (VAS 1-3)

3-Moderate pain (VAS 4-7)

4- Unbearable pain (VAS 8-10)

Patients were asked to assign a numerical score on the scale graphically or verbally to rate their pain intensity and the number was recorded.

\section{Statistical analysis}

Data were reviewed to check for any errors during data entry. The data were analyzed by the use of SPSS software (SPSS Statistics for Windows, version x.25 (SPSS Inc., Chicago, Ill., USA)). Descriptive statistics were calculated as 
frequencies and percentages for qualitative data while mean and standard deviation (SD) were used for quantitative data. Graphical presentation was done using bar and pie charts.

Since dropout was occurred during conducting the study, per protocol and intention to treat analysis were applied. Chi Square test was used to compare between the two study groups regarding all qualitative variables. Differences in VAS were assessed using Mann U Whitney test or Student's $\mathrm{t}$ test for not normally and normally distributed data, respectively. Percent change was calculated according to formula (( $2^{\text {nd }}$ assessment- $1^{\text {st }}$ assessment $) / 1^{\text {st }}$ assessment) $* 100$.

\section{RESULTS}

The present randomized controlled clinical trial was conducted to evaluate the effectiveness of melatonin in reducing the pain resulting from radiation induced oral mucositis.

This study included 40 patients who were assessed for eligibility and who fulfilled the selection criteria. These patients were randomly assigned to two equal groups. (20 patients per group) (I-test and II-control)

One patient from each group of patients had dropped out during the study. Therefore, a total of 38 patients completed the clinical trial following the intention to treat analysis.

As shown in table (1), the demographic characteristics in both groups were similar with no significant difference in the mean of the age. Regarding the gender distribution, equal male and female distribution was found in the test group while a male predominance was present in the control group.

[Table 1]

VAS scores are shown in figure 1 and figure 2. Figure 1 illustrates that Mean and standard deviation for VAS scores for test group were $(4.85 \pm 1.66$ and $5.25 \pm 1.97)$ for $1^{\text {st }}$ and $2^{\text {nd }}$ assessment respectively. Whereas, for the control group, VAS scores were $(5.25 \pm 2.84$ and $7.55 \pm 1.77)$ for $1^{\text {st }}$ and $2^{\text {nd }}$ assessment respectively. In addition, t test shows a statistically significant increase in pain score $(\mathrm{P}$ value $<0.001$ ) in the $2^{\text {nd }}$ assessment of the control group compared to test group whereas the paired $t$ test revealed no significant differences in mean scores of $1^{\text {st }}$ and $2^{\text {nd }}$ assessment within the same group of patients.

In Fig.2. A significant change occurred in the mean of VAS sores among study participants between the $1^{\text {st }}$ and $2^{\text {nd }}$ assessment.

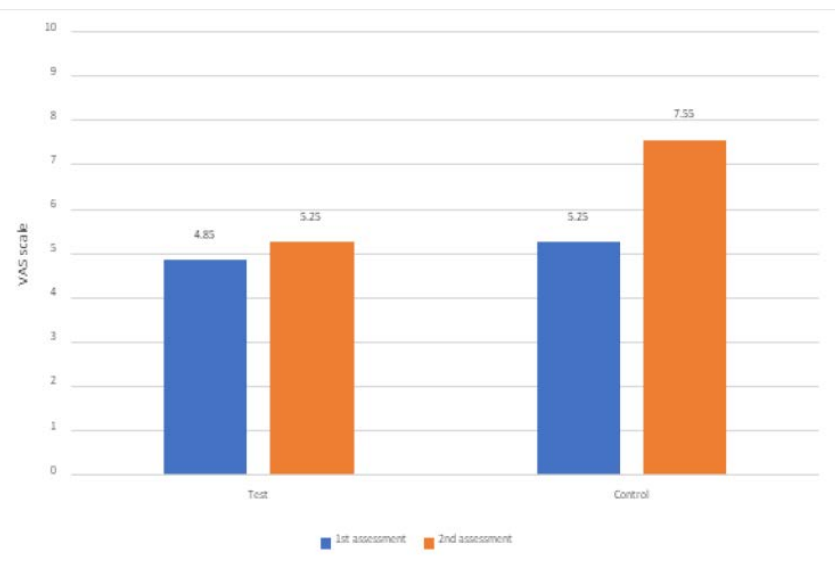

Figure (1): Changes in the mean of VAS scores among study participants using intention to treat analysis.

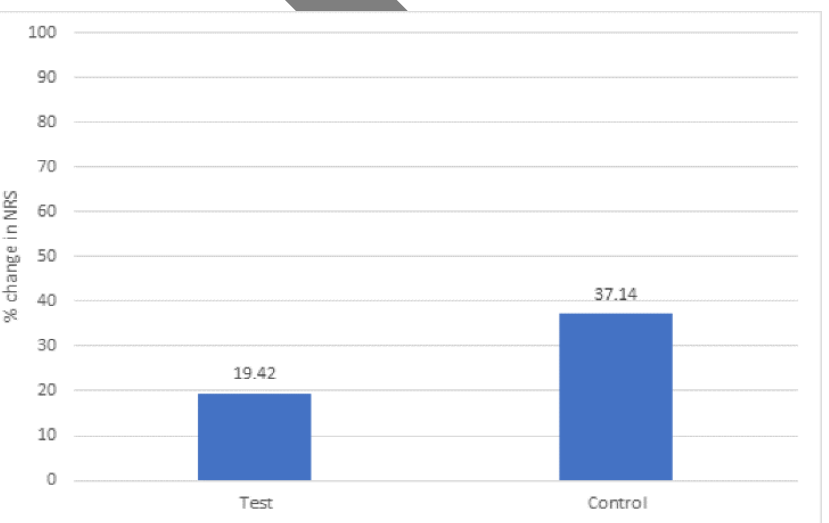

Figure (2): \% change in VAS scale among study participants using intention to treat analysis

Table (1): Demographic data of study sample

\begin{tabular}{|c|c|c|c|c|}
\hline & & $\begin{array}{l}\text { Test } \\
(\mathrm{n}=20)\end{array}$ & $\begin{array}{l}\begin{array}{l}\text { Control } \\
(\mathrm{n}=20)\end{array} \\
\end{array}$ & $\begin{array}{l}\mathbf{P} \\
\text { value }\end{array}$ \\
\hline \multicolumn{2}{|c|}{$\begin{array}{l}\text { Age: Mean } \pm \text { SD } \\
\text { years }\end{array}$} & $55.90 \pm 11.01$ & $57.80 \pm 10.32$ & $0.57^{\mathrm{a}}$ \\
\hline \multirow{2}{*}{$\begin{array}{l}\text { Gender: } \\
\text { n (\%) }\end{array}$} & Male & $10(50 \%)$ & $13(65 \%)$ & \multirow[t]{2}{*}{$0.33^{b}$} \\
\hline & Female & $10(50 \%)$ & $7(35 \%)$ & \\
\hline
\end{tabular}

a. Student's t test

b. Pearson Chi square

*: Significant difference $\mathrm{p}<0.05$

\section{DISCUSSION}

$\mathrm{OM}$ is a major consequence of the toxic effects of radiotherapy. Over $90 \%$ of those irradiated for head and neck cancer are expected to suffer from OM throughout or after the treatment period. It often causes serious pain and inflammation. Besides it can lead to malnutrition, bacterial infections, poor quality of life, and most importantly could cause interruption of the therapy protocol. The pineal hormone melatonin inhibits the development of free radicals which mediate tissue damage.(30) 
The main objective of this randomized controlled clinical trial was to evaluate the role of melatonin as an adjuvant treatment for reducing the pain resulting from $\mathrm{OM}$ developed in patients with head and neck cancer as a consequence of radiotherapy.

In the current trial, after 6 weeks from radiotherapy, patients of the control group who didn't receive melatonin in their preventive regimen demonstrated significantly more severe pain score when compared to those of the test group. This is in accordance with evidence from previous experimental(31-33) and clinical(34, 35) studies demonstrating the potent analgesic and anxiolytic effect of melatonin and reporting the use of melatonin for acute and chronic pain relief.

These consistent results may be explained by the fact that melatonin has been shown to improve pain control both in animal and human studies. (36) A study of 61 healthy subjects taking $0.05,0.15$, or $0.25 \mathrm{mg} / \mathrm{kg}$ sublingual melatonin showed well-defined dose- dependent analgesic activity, with correlation between the plasma drug concentration and acute changes in the pain threshold. (37) In a systematic review of randomized controlled trials of perioperative melatonin, including 24 studies and 1,794 participants, compared with placebo, melatonin reduced the standardized mean difference (95\% confidence interval [CI]) of postoperative pain score by $1.06(0.23-1.88)$. (38)

The analgesic effects of melatonin have not been explained to date. Numerous mechanisms are still being proposed. One such mechanism suggests that the analgesic effect of melatonin is linked to G1-coupled melatonin receptors, G1-coupled opioid m-receptors, or GABA-B receptors.(39)

In the current study, after three weeks, both groups have shown a medium pain score without any significant difference. This lack of significance could be referred to the short period of melatonin administration at the first follow up time point. This explanation was affirmed in a review article by Wilhelmsen et al.(36) which reported that the repeated administration of melatonin could reduce anxiety leading to lower levels of pain. It can therefore be suggested that the effects of melatonin as a possible analgesic depends on time.

\section{CONCLUSION}

The use of melatonin in combination with the conventional treatment has reduced the pain of oral mucositis, and the amount of analgesics used for pain treatment.

\section{CONFLICT OF INTEREST}

The authors declare that they have no conflicts of interest

\section{REFERENCES}

1.Epstein JB, Schubert MM. Managing pain in mucositis. Seminars in Oncology Nursing. 2004;20:30-7.

2.Vijayalaxmi, Reiter RJ, Tan DX, Herman TS, Thomas CR,

Jr. Melatonin as a radioprotective agent: a review.
International journal of radiation oncology, biology, physics. 2004;59:639-53.

3.Valko M, Leibfritz D, Moncol J, Cronin MT, Mazur M, Telser J. Free radicals and antioxidants in normal physiological functions and human disease. The international journal of biochemistry \& cell biology. 2007;39:44-84.

4.Harris DJ. Cancer treatment-induced mucositis pain: strategies for assessment and management. Ther Clin Risk Manag. 2006;2:251-8.

5.Maria OM, Eliopoulos N, Muanza T. Radiation-Induced Oral Mucositis. Frontiers in oncology. 2017;7:89.

6.Rubenstein EB, Peterson DE, Schubert M, Keefe D, McGuire D, Epstein J, et al. Clinical practice guidelines for the prevention and treatment of cancer therapyinduced oral and gastrointestinal mucositis. Cancer. 2004;100(9 Suppl):2026-46.

7.Sonis ST. Mucositis as a biological process: a new hypothesis for the development of chemotherapy-induced stomatotoxicity. Oral Oncol. 1998;34:39-43.

8.Dodd MJ, Miaskowski C, Shiba GH, Dibble SL, Greenspan D, Macphail L, et al. Risk factors for chemotherapy-induced oral mucositis: dental appliances, oral hygiene, previous oral lesions, and history of smoking. Cancer investigation. 1999;17:278-84.

9.Jham BC, Reis PM, Miranda EL, Lopes RC, Carvalho AL, Scheper MA, et al. Oral health status of 207 head and neck cancer patients before, during and after radiotherapy. Clinical oral investigations. 2008;12:19-24.

10. Raber-Durlacher JE, Elad S, Barasch A. Oral mucositis. Oral oncology. 2010;46:452-6.

11. Villa A, Sonis ST. Mucositis: pathobiology and management. Current opinion in oncology. 2015;27:15964.

12. Nicolatou-Galitis O, Sarri T, Bowen J, Di Palma M, Kouloulias VE, Niscola P, et al. Systematic review of amifostine for the management of oral mucositis in cancer patients. Support Care Cancer. 2013;21:357-64.

13. Moslehi A, Taghizadeh-Ghehi M, Gholami K, Hadjibabaie M, Jahangard-Rafsanjani Z, Sarayani A, et al. N-acetyl cysteine for prevention of oral mucositis in hematopoietic SCT: a double-blind, randomized, placebo-controlled trial. Bone marrow transplantation. 2014;49:818-23.

14. Hardeland R, Pandi-Perumal SR, Cardinali DP. Melatonin. The international journal of biochemistry \& cell biology. 2006;38:313-6.

15. Abdel Moneim AE, Ortiz F, Leonardo-Mendonca RC, Vergano-Villodres R, Guerrero-Martinez JA, Lopez LC, et al. Protective effects of melatonin against oxidative damage induced by Egyptian cobra (Naja haje) crude venom in rats. Acta tropica. 2015;143:58-65.

16. Reiter RJ, Melchiorri D, Sewerynek E, Poeggeler B, Barlow-Walden L, Chuang J, et al. A review of the evidence supporting melatonin's role as an antioxidant. $\mathrm{J}$ Pineal Res. 1995;18:1-11. 
17. Marshall KA, Reiter RJ, Poeggeler B, Aruoma OI, Halliwell B. Evaluation of the antioxidant activity of melatonin in vitro. Free radical biology \& medicine. 1996;21:307-15.

18. Vijayalaxmi, Meltz ML, Reiter RJ, Herman TS, Kumar KS. Melatonin and protection from whole-body irradiation: survival studies in mice. Mutation research. 1999;425:21-7.

19. Abdel Moneim AE, Guerra-Librero A, Florido J, Shen YQ, Fernandez-Gil B, Acuna-Castroviejo D, et al. Oral Mucositis: Melatonin Gel an Effective New Treatment. Int J Mol Sci. 2017;18.

20. Vijayalaxmi, Reiter RJ, Herman TS, Meltz ML. Melatonin and radioprotection from genetic damage: in vivo/in vitro studies with human volunteers. Mutation research. 1996;371:221-8.

21. Vijayalaxmi, Reiter RJ, Herman TS, Meltz ML. Melatonin reduces gamma radiation-induced primary DNA damage in human blood lymphocytes. Mutation research. 1998;397:203-8.

22. Wang YM, Jin BZ, Ai F, Duan CH, Lu YZ, Dong TF, et al. The efficacy and safety of melatonin in concurrent chemotherapy or radiotherapy for solid tumors: a metaanalysis of randomized controlled trials. Cancer Chemother Pharmacol. 2012;69:1213-20.

23. Mihandoost E, Shirazi A, Mahdavi SR, Aliasgharzadeh A. Can melatonin help us in radiation oncology treatments? Biomed Res Int. 2014;2014:578137.

24. World Medical Association Declaration of Helsinki: ethical principles for medical research involving human subjects. Jama. 2013;310:2191-4.

25. Moher D, Hopewell S, Schulz KF, Montori V, Gotzsche PC, Devereaux PJ, et al. CONSORT 2010 explanation and elaboration: updated guidelines for reporting parallel group randomised trials. BMJ. 2010;340:c869.

26. Killeen PR. An Alternative to Null-Hypothesis Significance Tests. Psychological science. 2005;16:34553.

27. Faul F, Erdfelder E, Lang AG, Buchner A. G*Power 3: a flexible statistical power analysis program for the social, behavioral, and biomedical sciences. Behavior research methods. 2007;39:175-91.

28. Schulz KF, Altman DG, Moher D. CONSORT 2010 statement: updated guidelines for reporting parallel group randomised trials. BMC medicine. 2010;8:18.

29. McGuire DB, Correa ME, Johnson J, Wienandts P. The role of basic oral care and good clinical practice principles in the management of oral mucositis. Support Care Cancer. 2006;14:541-7.

30. T Perchyonok V, Zhang S, Oberholzer T. Novel melatonin-chitosan hydrogels as suitable oral bio-drug delivery systems to fight oral mucositis: Synergy of antioxidants and bioactives in action. Current Organic Chemistry. 2012;16:2430-6.

31. Yu C-X, Zhu C-B, Xu S-F, Cao X-D, Wu G-C. The analgesic effects of peripheral and central administration of melatonin in rats. European journal of pharmacology. 2000;403:49-53.

32. Naguib M, Hammond D, Schmid III P, Baker M, Cutkomp J, Queral L, et al. Pharmacological effects of intravenous melatonin: comparative studies with thiopental and propofol. British journal of anaesthesia. 2003;90:504-7.

33. El-Shenawy SM, Abdel-Salam OM, Baiuomy AR, ElBatran S, Arbid MS. Studies on the anti-inflammatory and anti-nociceptive effects of melatonin in the rat. Pharmacological research. 2002;46:235-43.

34. Alstadhaug KB, Odeh F, Salvesen R, Bekkelund SI. Prophylaxis of migraine with melatonin: a randomized controlled trial. Neurology. 2010;75:1527-32.

35. Mozaffari S, Rahimi R, Abdollahi M. Implications of melatonin therapy in irritable bowel syndrome: a systematic review. Current pharmaceutical design. 2010;16:3646-55.

36. Wilhelmsen M, Amirian I, Reiter RJ, Rosenberg J, Gögenur I. Analgesic effects of melatonin: a review of current evidence from experimental and clinical studies. Journal of Pineal Research. 2011;51:270-7.

37. Stefani LC, Muller S, Torres IL, Razzolini B, Rozisky JR, Fregni F, et al. A Phase H, Randomized, DoubleBlind, Placebo Controlled, Dose-Response Trial of the Melatonin Effect on the Pain Threshold of Healthy Subjects. PloS one. 2013;8:e74107.

38. Andersen LP, Werner MU, Rosenberg J, Gogenur I. A systematic review of peri-operative melatonin. Anaesthesia. 2014;69:1163-71.

39. Wang T, Li S-r, Dai X, Peng Y-l, Chen Q, Wang R. Effects of melatonin on orphanin FQ/nociceptin-induced hyperalgesia in mice. Brain research. 2006;1085:43-8. 